\title{
Progression into sepsis: an individualized process varying by the interaction of comorbidities with the underlying infection
}

\author{
Dimitrios Sinapidis ${ }^{1}$, Vassileios Kosmas ${ }^{2}$, Vasileios Vittoros ${ }^{3}$, loannis M. Koutelidakis ${ }^{4}$, Aikaterini Pantazi ${ }^{5}$, \\ Aggelos Stefos ${ }^{6}$, Konstantinos E. Katsaros ${ }^{7}$, Karolina Akinosoglou ${ }^{8}$, Magdalini Bristianou ${ }^{9}$, Konstantinos Toutouzas $^{10}$, \\ Michael Chrisofos ${ }^{11}$ and Evangelos J. Giamarellos-Bourboulis ${ }^{12,13^{*}}$ (i)
}

\begin{abstract}
Background: Development of sepsis is a process with significant variation among individuals. The precise elements of this variation need to be defined. This study was designed to define the way in which comorbidities contribute to sepsis development.

Methods: Three thousand five hundred nine patients with acute pyelonephritis (AP), community-acquired pneumonia (CAP), intraabdominal infections (IAI) or primary bacteremia (BSI) and at least two signs of the systemic inflammatory response syndrome were analyzed. The study primary endpoint was to define how comorbidities as expressed in the Charlson's comorbidity index (CCl) and the underlying type of infection contribute to development of organ dysfunction. The precise comorbidities that mediate sepsis development and risk for death among 18 comorbidities recorded were the secondary study endpoints.

Results: CCI more than 2 had an odds ratio of 5.67 for sepsis progression in patients with IAl between significantly higher than AP and BSI. Forward logistic regression analysis indicated seven comorbidities that determine transition into sepsis in patients with AP, four comorbidities in CAP, six comorbidities in IAI and one in BSI. The odds ratio both for progression to sepsis and death with one comorbidity or with two and more comorbidities was greater than in the absence of comorbidities.
\end{abstract}

Conclusions: The study described how different kinds of infection vary in the degree to which they lead to sepsis. The number of comorbidities that enhances the risk of sepsis and death varies depending on the underlying infections.

Keywords: Infection, Sepsis, Comorbidities, Mortality, Intrabdominal

\section{Background}

Despite progress in our understanding of the mechanism of pathogenesis, sepsis remains a leading cause of death. The Sepsis-3 expert committee developed diagnostic criteria for sepsis in which co-morbidities played a considerable role. According to their analysis, clinical signs prognostic of the added risk for death to the risk coming from comorbidities were used to develop the diagnostic criteria for sepsis [1]. The Charlson's co-morbidity index (CCI) was applied by

\footnotetext{
* Correspondence: egiamarel@med.uoa.gr

${ }^{12} 4$ th Department of Internal Medicine, National and Kapodistrian University of Athens, Medical School, Athens, Greece

${ }^{13} 4$ th Department of Internal Medicine, ATTIKON University Hospital, 1 Rimini Street, 12462 Athens, Greece

Full list of author information is available at the end of the article
}

the Sepsis-3 expert panel as an expression of the co-morbidities [2].

Since 2006, the Hellenic sepsis study Group (HSSG) is collectively collecting clinical data for patients with infections presenting with at least two signs of the systemic inflammatory response syndrome (SIRS). Results from these studies on the traits of the innate and of the adaptive immune activation as well as on genotyping characteristics indicated that progression to organ dysfunction varied greatly among individuals and it was dependent on the type of infection [3, 4].

We have recently re-classified all the patients in our database into non-sepsis and sepsis according to the new Sepsis-3 definitions [5]. We asked the question if 
co-morbidities of patients admitted in the emergency department (ED) influence the development of organ dysfunction and whether this depends on the underlying infection. We tried to identify how each of the individual co-morbidities and how their constellation, expressed by the CCI, impacts on the development of organ failure and final outcome.

\section{Methods}

\section{Study design}

This is the analysis of the prospective collection of clinical information for patients admitted with at least two signs of SIRS at the ED of 38 hospitals in Greece from January 2007 until September 2016. The study protocol was approved by the Ethics Committees of the participating hospitals. Written informed consent was provided by the patients or by a legal representative in case of patients unable to consent. The study design and study endpoints were defined before the start of the study.

Inclusion criteria were: a) age equal to or more than 18 years; b) both genders; c) written informed consent; d) presence of at least two signs of SIRS as defined elsewhere [6]; and e) acute pyelonephritis (AP), community-acquired pneumonia (CAP), intraabdominal infections (IAI) and primary bacteremia (BSI) as the cause of SIRS. These infections were defined according to internationally accepted criteria [7-9]. Exclusion criteria were: a) age below 18 years; b) deny to consent; c) neutropenia defined as an absolute neutrophil count lower than $1000 / \mathrm{mm}^{3}$ for reason other than SIRS; and d) any metastatic solid tumor malignancy.

For all patients the following information was recorded: demographics, sequential organ failure assessment (SOFA) score, acute physiology and chronic health evaluation (APACHE) II score, CCI, co-morbidities and 28-day outcome. Eighteen comorbidities were recorded: type 2 diabetes mellitus, chronic heart failure, chronic obstructive pulmonary disorder (COPD), chronic renal disease, solid tumor malignancy, any hematological malignancy, chronic intake of corticosteroids, coronary heart disease, vascular hypertension, atrial fibrillation, dyslipidemia, obesity, history of stroke, dementia, nephrolithiasis, gallstones, liver cirrhosis and depression based on each patient medical history.

\section{Study endpoints}

The study primary endpoint was to define if $\mathrm{CCI}$ interacts additively with the underlying type of infection for the development of organ dysfunction. At the original study protocol, organ dysfunctions were defined by the 2001 definitions. After the publication of the new Sepsis-3 definitions, it was decided to re-classify all patients in the database as non-sepsis and sepsis based on total SOFA score equal to or more than 2 [5].
The study secondary endpoints were: a) the precise comorbidities that influence development of sepsis within the subgroups of patients with a specific infection; b) the influence of the number of comorbidities for the development of sepsis within the subgroups of patients with a specific infection; c) the precise comorbidities that impact on 28-day mortality within the subgroups of patients with a specific infection; d) the influence of the number of comorbidities on 28-day mortality within the subgroups of patients with a specific infection; and e) if comorbidities as expressed by the CCI have a different impact for 28-day mortality in relation to the underlying type of infection.

\section{Statistical analysis}

The Sepsis-3 expert panel has decided to introduce $90 \%$ sensitivity as the cut-off of discrimination in the analysis of Receiver Operator Characteristics (ROC) curves for variables that influence sepsis outcome [1]. As a consequence, we selected $90 \%$ sensitivity as the criterion to define a value of $\mathrm{CCI}$ that can discriminate an adequate probability for death after 28 days in the entire population. Specificity, positive and negative predictive value of the selected cut-off of CCI for 28-day mortality were also calculated. The odds ratio and 95\% confidence intervals (CIs) for sepsis compared to non-sepsis at the selected CCI cut-off was calculated for patients with and without a specific type of infection; ORs were compared by the Tarone's test. The same analysis of ORs was done for 28-day mortality. To define the role of each comorbidity, frequencies of each of the 18 comorbidities among non-sepsis and sepsis patients and among survivors and non-survivors were compared within each infection sub-group by the Fisher exact test. Comorbidities with a $p$-value of difference less than 0.05 entered a logistic forward conditional regression analysis to define the precise comorbidities that influence patients within each specific infection. The OR and $95 \%$ CIs for sepsis and for 28-day mortality in relation to the number of comorbidities was calculated; ORs were compared by the Tarone's test. Any value of p below 0.05 was considered significant.

\section{Results}

The study flow chart is shown in Fig. 1. A total of 3509 patients were analyzed; 2341 had sepsis as defined by the new Sepsis-3 definitions. The baseline characteristics of these patients are shown in Table 1.

\section{Primary study endpoint}

ROC curve analysis conducted in the overall study population showed that CCI more than 2 was accompanied by 89.3\% sensitivity (86.9-91.2\%) to predict 28-day mortality (Fig. 2). Figure 3 shows the ORs for the development of sepsis in relation to the underlying infection for patients 


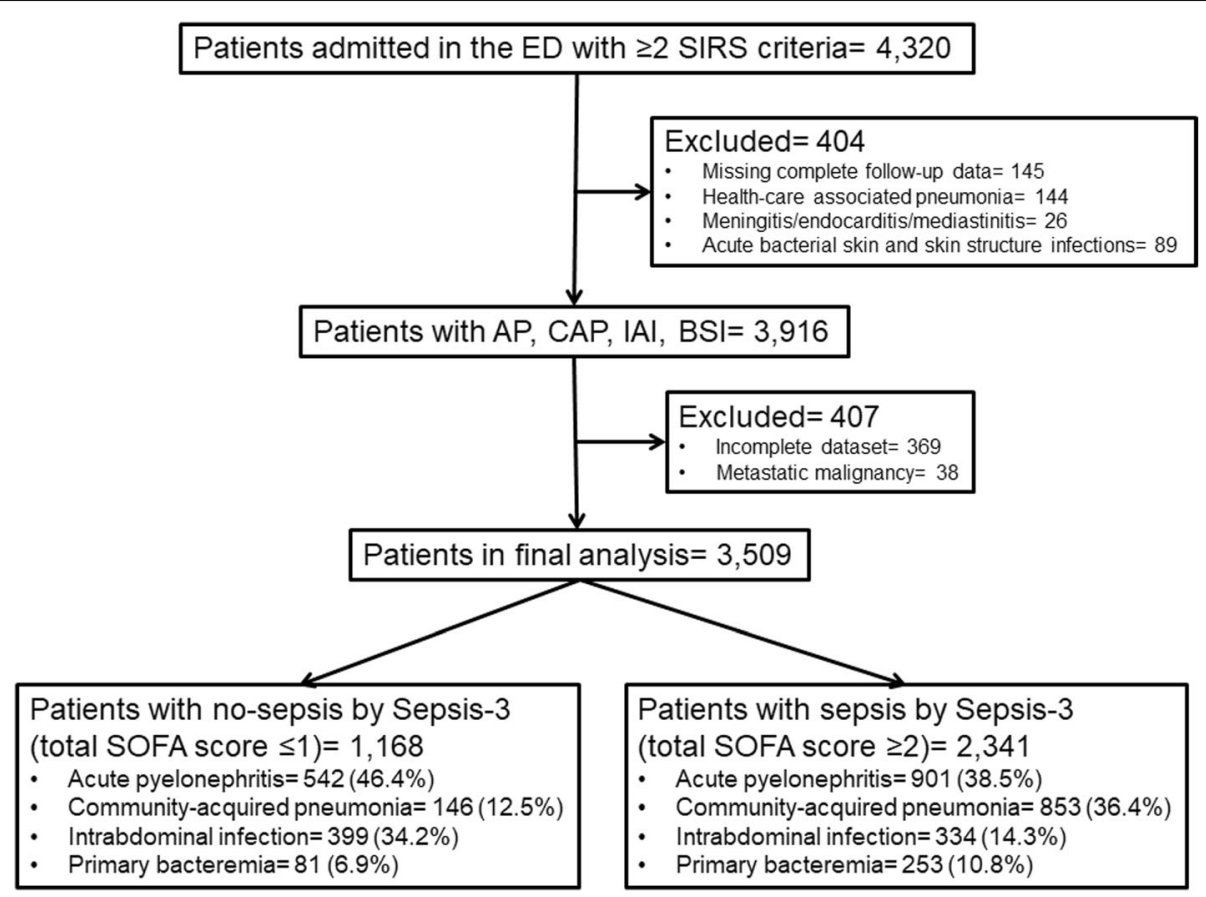

Fig. 1 Study flow chart. AP: acute pyelonephritis; BSI: primary bacteremia; CAP: community-acquired pneumonia; ED: emergency department; IAI: intraabdominal infection; SIRS: systemic inflammatory response syndrome; SOFA: sequential organ failure assessment

with CCI more than 2. Findings suggest that although the OR for sepsis was significantly increased under the pressure of CCI more than 2 for all types of infection, this effect was far more pronounced for patients with IAIs.

\section{Secondary study endpoints}

The next question was what the exact co-morbidities are that can enhance the development of sepsis among patients within each infection subgroup. At first, comparisons were done to define the comorbidities that differ between non-sepsis and sepsis patients within each infection subgroup. The analysis indicated 10 comorbidities that differ between non-sepsis and sepsis patients in the case of AP (Additional file 1: Table S1), seven comorbidities in the case of CAP (Additional file 2: Table S2), 11 comorbidities in the case of IAIs (Additional file 3: Table S3) and three

Table 1 Comparison of demographics of patients without sepsis and with sepsis in relation to the underlying infection

\begin{tabular}{|c|c|c|c|c|c|c|c|c|c|c|c|c|}
\hline & \multicolumn{3}{|c|}{ Acute pyelonephritis } & \multicolumn{3}{|c|}{$\begin{array}{l}\text { Community-acquired } \\
\text { pneumonia }\end{array}$} & \multicolumn{3}{|c|}{ Intra-abdominal infections } & \multicolumn{3}{|c|}{ Primary bacteremia } \\
\hline & No sepsis & Sepsis & $p$ & No sepsis & Sepsis & $p$ & No sepsis & Sepsis & $p$ & No sepsis & Sepsis & $p$ \\
\hline $\begin{array}{l}\text { Number of } \\
\text { patients }\end{array}$ & 542 & 901 & & 146 & 853 & & 399 & 334 & & 81 & 253 & \\
\hline $\begin{array}{l}\text { Male gender } \\
(n, \%)\end{array}$ & $145(26.8)$ & $361(40.0)$ & $<0.0001$ & $\begin{array}{l}78 \\
(53.4)\end{array}$ & $473(55.4)$ & 0.897 & $\begin{array}{l}180 \\
(45.2)\end{array}$ & $\begin{array}{l}148 \\
(45.1)\end{array}$ & 1.000 & $\begin{array}{l}40 \\
(49.4)\end{array}$ & $\begin{array}{l}123 \\
(48.6)\end{array}$ & 1.000 \\
\hline $\begin{array}{l}\text { Age } \\
\text { (mean } \pm S D \text {, years) }\end{array}$ & $61.1 \pm 22.0$ & $74.8 \pm 15.3$ & $<0.0001$ & $61.4 \pm 20.2$ & $75.3 \pm 14.9$ & $<0.0001$ & $55.4 \pm 24.3$ & $\begin{array}{l}74.7 \pm \\
14.8\end{array}$ & $<0.0001$ & $63.3 \pm 19.7$ & $72.9 \pm 14.5$ & $<0.0001$ \\
\hline $\begin{array}{l}\text { APACHE II score } \\
(\text { mean } \pm \text { SD) }\end{array}$ & $9.2 \pm 6.0$ & $16.5 \pm 7.4$ & $<0.0001$ & $8.4 \pm 4.8$ & $18.4 \pm 7.6$ & $<0.0001$ & $7.5 \pm 4.9$ & $17.5 \pm 8.9$ & $<0.0001$ & $9.2 \pm 4.6$ & $19.8 \pm 7.5$ & $<0.0001$ \\
\hline $\begin{array}{l}\text { SOFA score } \\
(\text { mean } \pm \mathrm{SD})\end{array}$ & $0.4 \pm 0.5$ & $5.9 \pm 3.0$ & $<0.0001$ & $0.7 \pm 0.5$ & $5.8 \pm 3.2$ & $<0.0001$ & $0.2 \pm 0.5$ & $5.3 \pm 3.0$ & $<0.0001$ & $0.5 \pm 0.5$ & $5.9 \pm 3.4$ & $<0.0001$ \\
\hline $\begin{array}{l}\mathrm{CCl} \\
(\text { mean } \pm \mathrm{SD})\end{array}$ & $3.0 \pm 2.5$ & $5.0 \pm 2.6$ & $<0.0001$ & $2.7 \pm 2.3$ & $4.8 \pm 2.4$ & $<0.0001$ & $2.3 \pm 2.3$ & $4.6 \pm 2.4$ & $<0.0001$ & $3.0 \pm 2.0$ & $4.5 \pm 2.4$ & $<0.0001$ \\
\hline $\begin{array}{l}\text { 28-day mortality } \\
(\mathrm{n}, \%)\end{array}$ & $\begin{array}{l}21 \\
(3.9)\end{array}$ & $208(23.1)$ & $<0.0001$ & $\begin{array}{l}7 \\
(4.8)\end{array}$ & $\begin{array}{l}323 \\
(37.9)^{*}\end{array}$ & $<0.0001$ & $\begin{array}{l}17 \\
(4.3)\end{array}$ & $\begin{array}{l}109 \\
(32.6)^{*}\end{array}$ & $<0.0001$ & $\begin{array}{l}4 \\
(4.9)\end{array}$ & $\begin{array}{l}98 \\
(38.6)^{*}\end{array}$ & $<0.0001$ \\
\hline
\end{tabular}

Abbreviations: APACHE acute physiology and chronic health evaluation, CCI Charlson's comorbidity index, SOFA sequential organ failure assessment ${ }^{*} p<0.0001$ compared to the respective mortality of acute pyelonephritis 


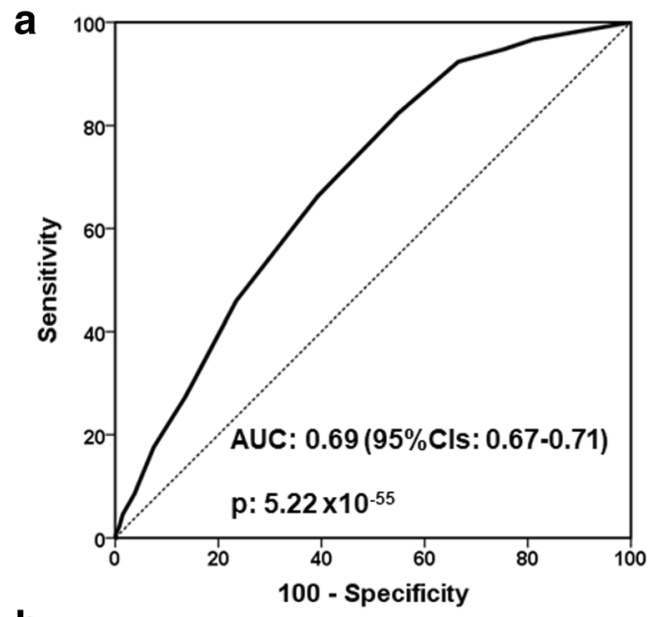

b

\begin{tabular}{|c|c|c|c|}
\hline & Dead & Alive & Total \\
\hline $\mathrm{CCl}>2$ & $\begin{array}{l}698 \\
\text { Se: } 89.3 \%(86.9-91.2) \\
\text { PPV: } 28.7 \%(26.9-30.5)\end{array}$ & 1736 & 2434 \\
\hline $\mathrm{CCl} \leq 2$ & 84 & $\begin{array}{l}991 \\
\text { Sp: } 36.3 \%(34.6-38.2) \\
\text { NPV: } 92.2 \%(90.4-93.6)\end{array}$ & 1075 \\
\hline Total & 782 & 2727 & 3509 \\
\hline
\end{tabular}

Fig. 2 Charlson's comorbidity index (CCI) influences final outcome. a ROC curve of CCI for 28-day mortality. b Prognostic performance of CCI more than 2 for 28-day mortality. NPV: negative predictive value; PPV: positive predictive value; Se: sensitivity; Sp: specificity

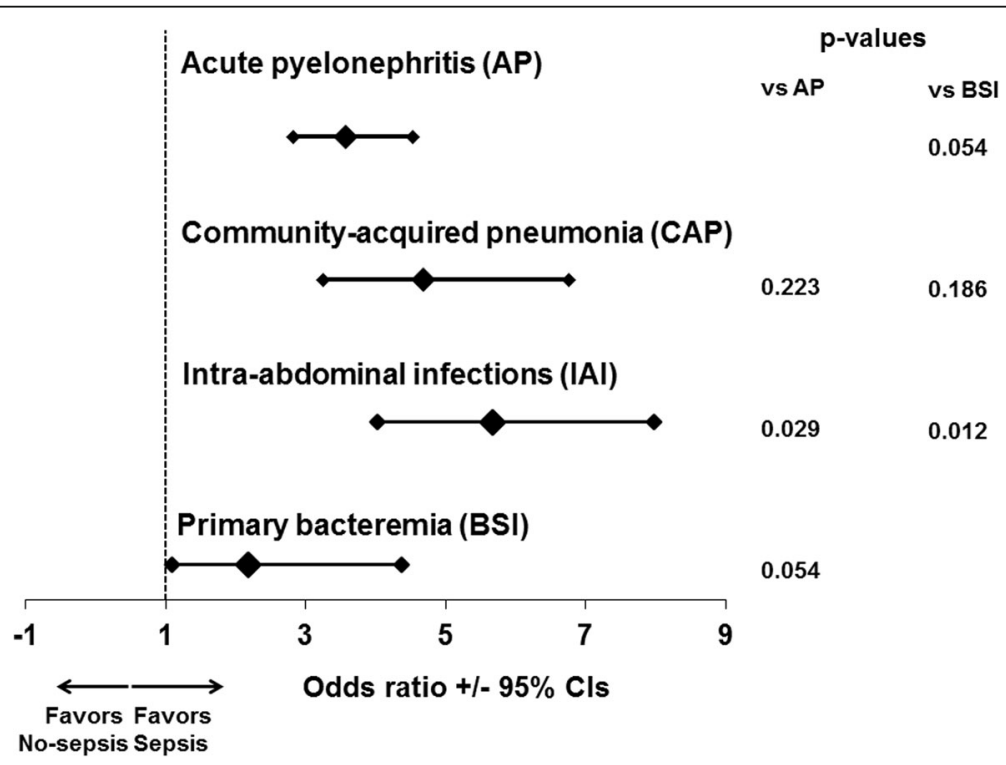

Fig. 3 Modulation of the risk for sepsis in relation to the underlying infection and the Charlson's comorbidity index (CCI). Each line represents the odds ratios and confidence intervals (Cl) for death of each individual infection when $\mathrm{CCl}$ is more than 2 compared to $\mathrm{CCl} \leq 2$. AP: acute pyelonephritis; BSI: primary bacteremia; CAP: community-acquired pneumonia; IAl: intraabdominal infection 
comorbidities in the case of BSI (Additional file 4: Table S4). These comorbidities entered into a logistic forward conditional regression analysis to conclude which are the precise comorbidities that are associated with the development of sepsis within each subgroup. Seven comorbidities were found in the case of AP, four in the case of CAP, six in the case of IAIs and only one in the case of BSI (Table 2). Among patients with type 2 diabetes mellitus, the need for intake of insulin for glycemic control did not modify the risk for sepsis compared to diabetic patients without insulin intake in the case of AP (OR: 1.29; 95\%CIs: 0.86-1.95; $p$ : 0.212), of CAP (OR: 1.15; 95\%CIs: 0.46-2.87; p: 0.761) and of IAIs (OR: 1.84; 95\%CIs: 0.87-3.90; p: 0.113). Among patients with chronic heart failure, those at end stage had greater risk for sepsis in the case of AP (OR: 5.40; 95\%CIs: 2.22-13.14; $p<0.0001$ ) but not of CAP (OR: 1.73; 95\%CIs: 0.54-5.56; $p: 0.357)$. Among patients with chronic renal disease, the number of patients who developed sepsis and who were on chronic hemodialysis was too low to allow stratification by disease severity.

Table 2 Impact of precise co-morbidities on the development of sepsis

\begin{tabular}{|c|c|c|c|}
\hline Co-morbidity & $\begin{array}{l}\text { Odds } \\
\text { ratio }\end{array}$ & $\begin{array}{l}95 \% \text { confidence } \\
\text { intervals }\end{array}$ & $p$-value \\
\hline \multicolumn{4}{|c|}{ Patients with acute pyelonephritis } \\
\hline Type 2 diabetes mellitus & 1.31 & $1.02-1.68$ & 0.033 \\
\hline Chronic heart failure & 1.93 & $1.39-2.69$ & $<0.0001$ \\
\hline Chronic renal disease & 29.31 & $9.26-92.86$ & $<0.0001$ \\
\hline $\begin{array}{l}\text { Non-metastatic solid tumor } \\
\text { malignancy }\end{array}$ & 2.03 & $1.40-2.89$ & $<0.0001$ \\
\hline Corticosteroid intake & 2.08 & $1.08-3.98$ & 0.028 \\
\hline Stroke & 1.70 & $1.21-2.39$ & 0.002 \\
\hline Dementia & 1.97 & $1.37-2.84$ & $<0.0001$ \\
\hline \multicolumn{4}{|c|}{$\begin{array}{l}\text { Patients with community-acquired } \\
\text { pneumonia }\end{array}$} \\
\hline Type 2 diabetes mellitus & 1.73 & $1.06-2.82$ & 0.027 \\
\hline Chronic heart failure & 1.99 & $1.13-3.49$ & 0.016 \\
\hline Coronary heart disease & 3.72 & $1.69-8.19$ & 0.001 \\
\hline Dementia & 3.44 & $1.64-7.24$ & 0.001 \\
\hline \multicolumn{4}{|l|}{$\begin{array}{l}\text { Patients with intraabdominal } \\
\text { infections }\end{array}$} \\
\hline Type 2 diabetes mellitus & 3.29 & $2.15-5.03$ & $<0.0001$ \\
\hline Chronic renal disease & 26.77 & $3.51-204.37$ & 0.002 \\
\hline Corticosteroid intake & 3.86 & $1.41-10.53$ & 0.008 \\
\hline Atrial fibrillation & 2.73 & $1.41-5.28$ & 0.003 \\
\hline Dementia & 9.33 & $3.79-22.97$ & $<0.0001$ \\
\hline Liver cirrhosis & 9.16 & $1.06-79.53$ & 0.044 \\
\hline \multicolumn{4}{|l|}{ Patients with primary bacteremia } \\
\hline Dementia & 8.55 & $1.12-65.20$ & 0.038 \\
\hline
\end{tabular}

Only variables remaining significant after the final step of logistic forward conditional regression analysis are included
One major question was whether the number of comorbidities may influence the susceptibility for sepsis. Figure 4 shows the ORs for sepsis for each individual infection under the pressure of one or at least two comorbidities compared to the absence of comorbidities. Even the presence of at least one of the comorbidities listed in Table 2 increased significantly the risk for sepsis. In all types of infection, the OR under the pressure of two or more comorbidities was significantly greater than under the pressure of only one comorbidity.

The comorbidities found in Table 2 to impose considerably for the development of sepsis entered into a logistic forward conditional regression analysis to decipher their impact on 28-day mortality within infection subgroups. Six comorbidities were found in the case of AP, two in the case of CAP, six in the case of IAIs and only one in the case of BSI (Table 3). Among patients with chronic heart failure, those at end stage had greater risk for sepsis in the case of AP (OR: 1.18; 95\%CIs: 0.68-2.05; p: 0.543). Among patients with type 2 diabetes mellitus, the need for intake of insulin for glycemic control did not modify the risk for death in the case of IAIs (OR: 1.21; 95\%CIs: 0.58-2.51; p: 0.607).

Figure 5 shows the odds ratios for death by each infection under the pressure of one or at least two comorbidities compared to the absence of comorbidities. Even the presence of at least one of the comorbidities listed in Table 3 significantly increased the risk for death. In all types of infection, the OR for death under the pressure of two or more comorbidities was significantly greater than under the pressure of only one comorbidity.

Although the OR for 28-day mortality was significantly increased under the pressure of CCI more than 2 for all types of infection, this effect was far more pronounced for patients with IAIs (Fig. 6).

\section{Discussion}

The present analysis managed to demonstrate that the risk for the development of sepsis, as this is defined by the new Sepsis-3 definitions, is modified in an individualized way in relation to the type of underlying infection. Findings clearly showed that comorbidities increased considerably the risk for sepsis and for unfavorable outcome after 28-days and that this effect varied greatly with the number of existing comorbidities. When using CCI as an expression of the constellation of comorbidities of the host, it was found that the susceptibility for both the development of sepsis and death after 28 days was far greater under the pressure of CCI more than 2 in intraabdominal infections that with any other type of infection. Regarding the influence of individual comorbidities, some comorbidities like type 2 diabetes mellitus, chronic renal disease and dementia were associated with sepsis risk in almost all types of infection. Others like chronic heart disease and non-metastatic tumor malignancy introduced sepsis risk in CAP and IAI, whereas 


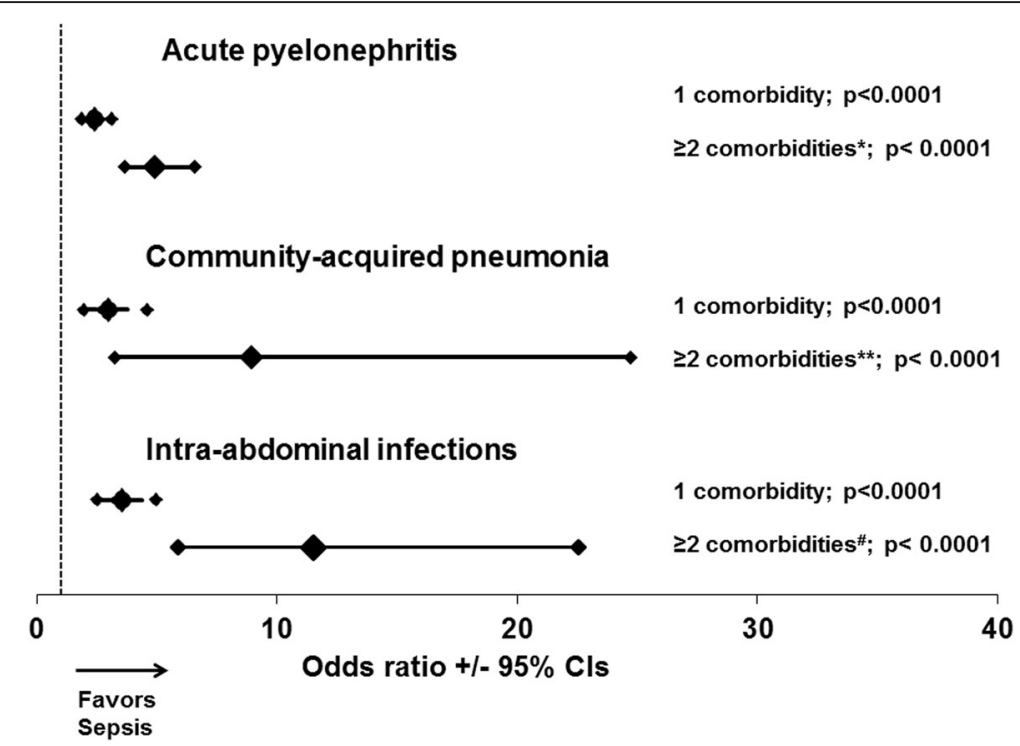

Fig. 4 Modulation of the risk for sepsis in relation to the underlying infection and the number of comorbidities. Each line represents the odds ratios and confidence intervals (Cl) for sepsis in the presence of one or at least two comorbidities, as defined for each infection in Table 1. $P$ values represent comparisons with patients without any comorbidity. The $p$-values of comparisons between odds ratio for one comoborditiy and for at least two comorbidities are: *0.00002; **0.033; ${ }^{*} 0.0018$

Table 3 Impact of precise co-morbidities on 28-day mortality

\begin{tabular}{|c|c|c|c|}
\hline Co-morbidity & $\begin{array}{l}\text { Odds } \\
\text { ratio }\end{array}$ & $\begin{array}{l}95 \% \text { confidence } \\
\text { intervals }\end{array}$ & $p$-value \\
\hline \multicolumn{4}{|l|}{$\begin{array}{l}\text { Patients with acute } \\
\text { pyelonephritis }\end{array}$} \\
\hline Chronic heart failure & 2.54 & $1.82-3.55$ & $<0.0001$ \\
\hline Chronic renal disease & 1.71 & $1.13-2.60$ & 0.011 \\
\hline $\begin{array}{l}\text { Non-metastatic solid } \\
\text { tumor malignancy }\end{array}$ & 2.13 & $1.44-3.17$ & $<0.0001$ \\
\hline Corticosteroid intake & 2.05 & $1.09-3.84$ & 0.024 \\
\hline Stroke & 2.97 & $2.12-4.17$ & $<0.0001$ \\
\hline Dementia & 2.18 & $1.51-3.15$ & $<0.0001$ \\
\hline \multicolumn{4}{|l|}{$\begin{array}{l}\text { Patients with community- } \\
\text { acquired pneumonia }\end{array}$} \\
\hline Coronary heart disease & 1.87 & $1.30-2.69$ & 0.001 \\
\hline Dementia & 2.20 & $1.53-3.17$ & $<0.0001$ \\
\hline \multicolumn{4}{|l|}{$\begin{array}{l}\text { Patients with intraabdominal } \\
\text { infections }\end{array}$} \\
\hline Type 2 diabetes mellitus & 1.84 & $1.16-2.93$ & 0.010 \\
\hline Chronic renal disease & 2.67 & $1.12-6.35$ & 0.026 \\
\hline $\begin{array}{l}\text { Non-metastatic solid tumor } \\
\text { malignancy }\end{array}$ & 3.03 & $1.79-5.13$ & $<0.0001$ \\
\hline Atrial fibrillation & 2.23 & $1.11-4.48$ & 0.024 \\
\hline Dementia & 3.69 & $1.87-7.25$ & $<0.0001$ \\
\hline Liver cirrhosis & 4.59 & $1.20-17.51$ & 0.025 \\
\hline \multicolumn{4}{|l|}{$\begin{array}{l}\text { Patients with primary } \\
\text { bacteremia }\end{array}$} \\
\hline Dementia & 3.87 & $1.65-9.12$ & 0.002 \\
\hline
\end{tabular}

Only variables remaining significant after the final step of logistic forward conditional regression analysis are included coronary heart disease introduced risk only in CAP. Atrial fibrillation and liver cirrhosis increased sepsis risk only in IAI. Surprisingly, the risk for sepsis after BSI was increased only in demented patients. A similar pattern was found regarding the impact of each comorbidity on 28-day mortality. It should be underscored that risk for sepsis and death was not significantly modified among patients with advanced type 2 diabetes mellitus and chronic heart failure compared to the less advanced disease state.

There is a great difference between susceptibility to an infection and susceptibility to inflammation. Many studies have shown the role of type 2 diabetes mellitus, solid tumor and hematologic malignancies, liver cirrhosis, atrial fibrillation and coronary heart disease for susceptibility to infections [6-10]. In this study, we try to define which comorbidities elicit progression to organ dysfunction once an infection has started. Of course this cannot be done with comparison of infected patients with healthy controls. Instead we compared various non-serious with serious community-acquired infections admitted to the ED. Our findings agree at some aspects and disagree at some other aspects with the current ideas about comorbidities that define risk for severity. A typical example is the case of CAP. Severity of CAP is defined by the pneumonia severity index (PSI) in which the history of five disorders i.e. neoplastic disease, congestive heart failure, cerebrovascular disease, renal disease and liver disease are taken into consideration [11]. Our analysis shows that among these five comorbidities only chronic heart disease leads the development of organ dysfunction. 


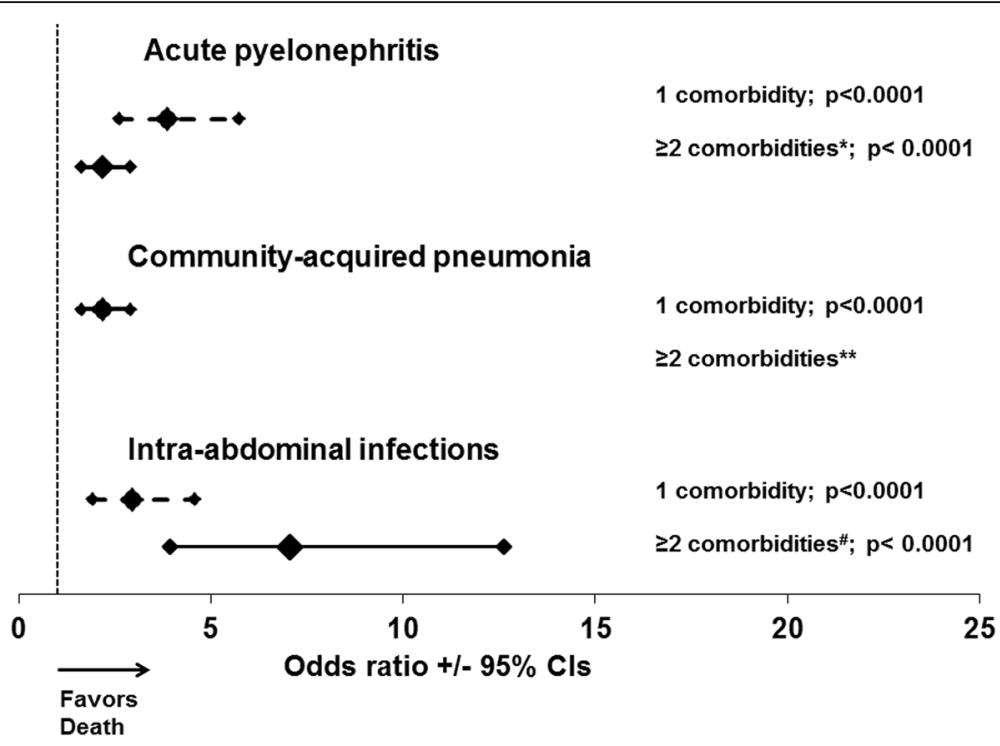

Fig. 5 Modulation of the risk for death after 28 days in relation to the underlying infection and the number of comorbidities. Each line represents the odds ratios and confidence intervals $(\mathrm{Cl})$ for death in the presence of one or at least two comorbidities, as defined for each infection in Table 2. $P$ values represent comparisons with patients without any comorbidity. The $p$-values of comparisons between odds ratio for one moborditiy and for at least two comorbidities are: ${ }^{*} 0.00002 ;{ }^{*} 0.0029 .{ }^{* *}$ could not be calculated because one value was zero

The impact of diabetes mellitus type 2 on the final outcome of patients with sepsis is a matter of debate. A comparison of the mortality of 241 diabetic patients and 863 non-diabetic patients with sepsis was done in the prospective cohort of the Molecular Diagnosis and Risk Stratification of Sepsis (MARS) project of two large academic centers in the Netherlands [12]. No difference in both short- and long-term outcomes was found and this was accompanied with lack of differences in the levels of circulating biomarkers for inflammation, coagulation and endothelial activation. The same lack of effect on clinical outcomes and concentrations of biomarkers was found after adjustment for treatment with insulin and metformin [12]. This finding corroborates our results on

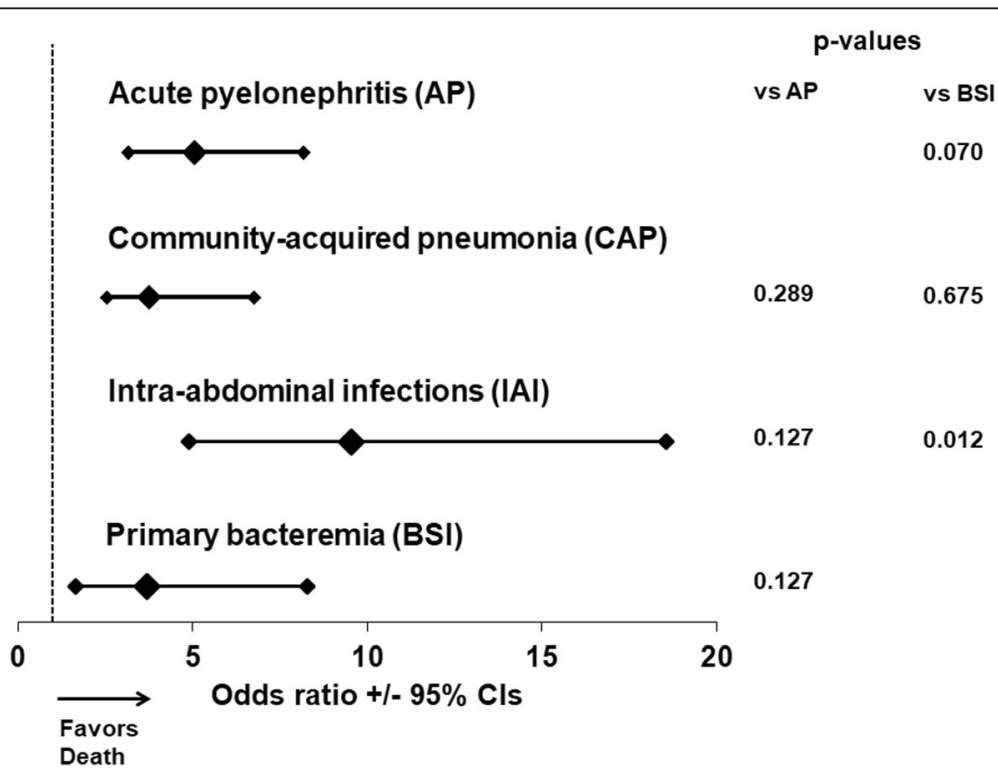

Fig. 6 Modulation of the risk for 28-day mortality in relation to the underlying infection and the Charlson's comorbidity index (CCI). Each line represents the odds ratios and confidence intervals $(\mathrm{Cl})$ for death of each individual infection when $\mathrm{CCl}$ is more than 2 compared to $\mathrm{CCl} \leq 2$. $P$-values are compared by the Tarone's test. AP: acute pyelonephritis; BSI: primary bacteremia; CAP: community-acquired pneumonia; IAI: intraabdominal infection 
the lack of effect of type 2 diabetes mellitus as a risk factor for 28-day mortality in AP and CAP. The impact of type 2 diabetes on the final outcome of CAP was also studied in two big cohorts, the GenIMS of 1895 subjects with CAP and the Health ABC of 1645 subjects. Mortality was greater among patients with diabetes than without diabetes [13]. At first reading, this finding is opposite to the lack of association between type 2 diabetes and mortality from CAP described in our study. However, diabetic patients of the GenIMS and Health $\mathrm{ABC}$ cohorts had greater risk for death by cardiovascular events [13]. This is partly compatible with our finding for coronary heart disease as an independent risk factor for death in CAP.

Sepsis is a multifactorial process and staging is necessary to provide personalized treatment targeting the needs of each patient. This concept has been introduced may years ago where the PIRO system was introduced. The acronym of PIRO stands for predisposition through comorbidities, infection, response of the host and organ dysfunction [6]. Our analysis showed for the first time an additive interaction between comorbidities and IAIs that increased the likelihood for sepsis and unfavorable outcome far more than the other types of infection. The data make clear that the PIRO system should separately stage the significance of the six comorbidities affecting outcome in IAI.

\section{Conclusion}

The results of our study generate the need to consider development of sepsis and organ dysfunction after an infection an individualized process. Comorbidities play a major role in this process. However, the comorbidities which facilitate progression into organ dysfunction vary according to the underlying infection. Among all type of infections, IAIs act additively with the comorbidities of the host to potentiate the likelihood for sepsis and the risk for unfavorable outcome at an extent much greater than the other infections.

\section{Additional files}

Additional file 1: Table S1. Comparison of comorbidities between patients with infection and sepsis developing in the field of acute pyelonephritis. (DOCX $21 \mathrm{~kb}$ )

Additional file 2: Table S2. Comparison of comorbidities between patients with infection and sepsis developing in the field of communityacquired pneumonia. (DOCX $21 \mathrm{~kb}$ )

Additional file 3: Table S3. Comparison of comorbidities between patients with infection and sepsis developing in the field of intraabdominal infections. (DOCX $20 \mathrm{~kb}$ )

Additional file 4: Table S4. Comparison of comorbidities between patients with infection and sepsis developing in the field of primary bacteremia. (DOCX $21 \mathrm{~kb})$

\section{Abbreviations}

AP: Acute pyelonephritis; APACHE: Acute physiology and chronic health evaluation; BSI: Primary bacteremia; CAP: Community-acquired pneumonia; CCl: Charlson's co-morbidity index; COPD: Chronic obstructive pulmonary disorder; ED: Emergency department; HSSG: Hellenic sepsis study group; IAI: Intraabdominal infections; MARS: Molecular Diagnosis and Risk

Stratification of Sepsis; PSI: Pneumonia severity index; ROC: Receiver Operator

Characteristics; SIRS: Systemic inflammatory response syndrome;

SOFA: Sequential organ failure assessment

\section{Funding}

The study was funded by the Hellenic Institute for the Study of Sepsis.

Availability of data and materials

Data are available upon request by the corresponding author.

\section{Authors' contributions}

DS participated in subjects' enrolment, drafted the manuscript and gave approval to the final version for submission. VK, W, IMK, AP, AS, KEK, KA, MB, $K T$ and $M C$ participated in subjects' enrolment, reviewed the manuscript for intellectual content and gave approval to the final version for submission. EJGB designed the study, analyzed the data, drafted the manuscript and gave approval to the final version for submission.

Ethics approval and consent to participate

The protocol was approved by the following Ethics Committees:

- Ethics Committee of "Alexandra" General Hospital of Athens

- Ethics Committee of 251 Air Force General Hospital of Athens

- Ethics Committee of ATTIKON University General Hospital of Athens

- Ethics Committee of Asklipieion General Hospital of Voula, Territory of Athens

- Ethics Committee of "Center for Trauma Resuscitation- KAT" General Hospital of Athens

- Ethics Committee of "Evangelismos" General Hospital of Athens

- Ethics Committee of "Evgenideio" Hospital of Athens

- Ethics committee of "Hippokrateio" General Hospital of Athens

- Ethics committee of "Hygeia" General Hospital of Athens

- Ethics Committee of "G. Gennimatas" General Hospital of Athens

- Ethics Committee of "Laikon" General Hospital of Athens

- Ethics Committee of "Konstantopouleio-Aghia Olga" General Hospital of Athens

- Ethics Committee of "Korgialeneion-Benakion" General Hospital of Athens

- Ethics Committee of "Sismanogleion" General Hospital of Athens

- Ethics Committee of "Sotiria" Athens General Hospital

- Ethics Committee of "Thriasio" Elefsis General Hospital Territory of Athens

- Ethics Committee of "Aghios Dimitrios" General Hospital of Thessaloniki

- Ethics Committee of "G. Gennimatas" General Hospital of Thessaloniki

- Ethics Committee of "Aghios Pavlos" General Hospital of Thessaloniki

- Ethics Committee of "Theagenio" Hospital of Thessaloniki

- Ethics Committee of "Metaxa" Hospital of Piraeus

- Ethics Committee of "Tzaneio" General Hospital of Piraeus

- Ethics committee of University General Hospital of Alexandroupolis

- Ethics Committee of General Hospital of Argos

- Ethics Committee of General Hospital of Arta

- Ethics committee of General Hospital of Chios

- Ethics Committee of University General Hospital of Ioannina

- Ethics Committee of General Hospital of Karditsa

- Ethics Committee of General Hospital of Korinthos

- Ethics Committee of General Hospital of Lamia

- Ethics Committee of University General Hospital of Larisa

- Ethics Committee of General Hospital of Nicosia

- Ethics committee of General Hospital of Nafplion

- Ethics Committee of University General Hospital of Patras

- Ethics Committee of General Hospital of Ptolemaida 
- Ethics Committee of General Hospital of Sparti

- Ethics Committee of General Hospital of Trikala

- Ethics Committee of General Hospital of Zakynthos

Written informed consent was provided by the patients or by a legal representative in case of patients unable to consent.

\section{Competing interests}

EJ Giamarellos-Bourboulis has received honoraria (paid to the University of Athens) from AbbVie, Biotest, Brahms GmbH, and The Medicines Company; he has received compensation as a consultant for Astellas Greece (paid to the University of Athens); and has received independent educational grants (paid to the University of Athens) from AbbVie, Biotest, and Sanofi. He is funded by the FrameWork 7 program HemoSpec and by the Horizon 2020 program European Sepsis Academy (granted to the University of Athens). None of the other authors has any other type of financial conflict to disclose. The other authors declare that they have no competing interests.

\section{Publisher's Note}

Springer Nature remains neutral with regard to jurisdictional claims in published maps and institutional affiliations.

\section{Author details}

${ }^{1}$ Department of Therapeutics, National and Kapodistrian University of Athens, Medical School, Athens, Greece. ${ }^{2} 1$ st Department of Internal Medicine, "G.Gennimatas" Athens General Hospital, Athens, Greece. ${ }^{3} 1$ st Department of Internal Medicine, Thriasio Elefsis General Hospital, Magoula, Greece. ${ }^{4}$ 2nd Department of Surgery, Aristotle University of Thessaloniki, Thessaloniki, Greece. ${ }^{5}$ 2nd Department of Internal Medicine, Thriasio Elefsis General Hospital, Magoula, Greece. ${ }^{6}$ Department of Medicine and Research Laboratory of Internal Medicine, Larissa University Hospital, University of Thessaly, Medical School, Volos, Greece. ${ }^{7}$ Department of Surgery, Nafplion General Hospital, Nafplio, Greece. ${ }^{8}$ Department of Internal Medicine, University of Patras, Rion, Greece. 'Department of Internal Medicine, Lamia General Hospital, Lamia, Greece. ${ }^{10} 1$ st Department of Propedeutic Surgery, National and Kapodistrian University of Athens, Medical School, Athens, Greece. ${ }^{11}$ 2nd Department of Urology, National and Kapodistrian University of Athens, Medical School, Athens, Greece. ${ }^{12} 4$ th Department of Internal Medicine, National and Kapodistrian University of Athens, Medical School, Athens, Greece. ${ }^{13} 4$ th Department of Internal Medicine, ATTIKON University Hospital, 1 Rimini Street, 12462 Athens, Greece.

Received: 27 June 2017 Accepted: 21 May 2018

Published online: 29 May 2018

\section{References}

1. Singer M, Deutschman CS, Seymour CW, Shankar-Hari M, Annane D, Bauer M, Bellomo R, Bernard GR, Chiche JD, Coopersmith CM, Hotchkiss RS, Levy MM, Marshall JC, Martin GS, Opal SM, Rubenfeld GD, van der Poll T, Vincent $J$, Angus DC. The third international consensus definitions for Sepsis and septic shock (Sepsis-3). JAMA. 2016;315(8):801-10.

2. Charlson ME, Pompei $P$, Ales KL, MacKenzie CR. A new method of classifying prognostic comorbidity in longitudinal studies: development and validation. J Chronic Dis. 1987;40(5):373-83.

3. Gogos C, Kotsaki A, Pelekanou A, Giannikopoulos G, Vaki I, Maravitsa P, Adamis S, Alexiou Z, Andrianopoulos G, Antonopoulou A, Athanassia S, Baziaka F, Charalambous A, Christodoulou S, Dimopoulou I, Floros I, Giannitsioti E, Gkanas P, loakeimidou A, Kanellakopoulou K, Karabela N, Karagianni V, Katsarolis I, Kontopithari G, Kopterides P, Koutelidakis I, Koutoukas P, Kranidioti H, Lignos M, Louis K, Lymberopoulou K, Mainas E, Marioli A, Massouras C, Mavrou I, Mpalla M, Michalia M, Mylona H, Mytas V, Papanikolaou I, Papanikolaou K, Patrani M, Perdios I, Plachouras D, Pistiki A, Protopapas K, Rigaki K, Sakka V, Sartzi M, Skouras V, Souli M, Spyridaki A Strouvalis I, Tsaganos T, Zografos G, Mandragos K, Klouva-Molyvdas P, Maggina N, Giamarellou H, Armaganidis A, Giamarellos-Bourboulis EJ. Early alterations of the innate and adaptive immune statuses in sepsis according to the type of underlying infection. Crit Care. 2010;14(3):R96.

4. Georgitsi MD, Vitoros V, Panou C, Tsangaris I, Aimoniotou E, Gatselis NK, Chasou E, Kouliatsis G, Leventogiannis K, Velissaris D, Belesiotou E, DioritouAggaliadou O, Giannitsioti E, Netea MG, Giamarellos-Bourboulis EJ,
Giannikopoulos G, Alexiou Z, Voloudakis N, Koutsoukou A. Individualized significance of the $-251 \mathrm{a} / T$ single nucleotide polymorphism of interleukin8 in severe infections. Eur J Clin Microbiol Infect Dis. 2016;35(4):563-70.

5. Giamarellos-Bourboulis EJ, Tsaganos T, Tsangaris I, Lada M, Routsi C, Sinapidis D, Koupetori M, Bristianou M, Adamis G, Mandragos K, Dalekos GN, Kritselis I, Giannikopoulos G, Koutelidakis I, Pavlaki M, Antoniadou E, Vlachogiannis G, Koulouras V, Prekates A, Dimopoulos G, Koutsoukou A, Pnevmatikos I, loakeimidou A, Kotanidou A, Orfanos SE, Armaganidis A, Gogos C. Validation of the new Sepsis-3 definitions: proposal for improvement in early risk identification. Clin Microbiol Infect. 2017;23(2):104-9.

6. Trevelin SC, Carlos D, Beretta M, da Silva JS, Cunha FQ. Diabetes mellitus and Sepsis: a challenging association. Shock. 2017;47(3):276-87.

7. Kim Y, Wie SH, Chang UI, Kim J, Ki M, Cho YK, Lim SK, Lee JS, Kwon KT, Lee $\mathrm{H}$, Cheong HJ, Park DW, Ryu SY, Chung MH, Pai H. Comparison of the clinical characteristics of diabetic and non-diabetic women with community-acquired acute pyelonephritis: a multicenter study. J Inf Secur. 2014;69(3):244-51.

8. Garcia-Vidal C, Ardanuy C, Gudiol C, Cuervo G, Calatayud L, Bodro M, Duarte R, Fernandez-Sevilla A, Antonio M, Linares J, Carratala J. Clinical and microbiological epidemiology of Streptococcus pneumoniae bacteremia in cancer patients. J Inf Secur. 2012;65(6):521-7.

9. Gustot T, Felleiter P, Pickkers P, Sakr Y, Rello J, Velissaris D, Pierrakos C, Taccone FS, Sevcik P, Moreno C, Vincent JL. Impact of infection on the prognosis of critically ill cirrhotic patients: results from a large worldwide study. Liver Int. 2014;34(10):1496-503.

10. Zhu J, Zhang X, Shi G, Yi K, Tan X. Atrial fibrillation is an independent risk factor for hospital-acquired pneumonia. PLoS One. 2015;10(7):e0131782.

11. Fine MJ, Auble TE, Yealy DM, Hanusa BH, Weissfeld LA, Singer DE, Coley CM, Marrie TJ, Kapoor WN. A prediction rule to identify low-risk patients with community-acquired pneumonia. N Engl J Med. 1997;336(4):243-50.

12. van Vught LA, Scicluna BP, Hoogendijk AJ, Wiewel MA, Klein Klouwenberg PM, Cremer OL, Horn J, Nurnberg P, Bonten MM, Schultz MJ, van der Poll T. Association of diabetes and diabetes treatment with the host response in critically ill sepsis patients. Crit Care. 2016;20(1):252.

13. Yende $S$, van der Poll $T$, Lee $M$, Huang DT, Newman $A B$, Kong $L$, Kellum JA, Harris TB, Bauer D, Satterfield S, Angus DC. The influence of pre-existing diabetes mellitus on the host immune response and outcome of pneumonia: analysis of two multicentre cohort studies. Thorax. 2010;65(10):870-7.

\section{Ready to submit your research? Choose BMC and benefit from:}

- fast, convenient online submission

- thorough peer review by experienced researchers in your field

- rapid publication on acceptance

- support for research data, including large and complex data types

- gold Open Access which fosters wider collaboration and increased citations

- maximum visibility for your research: over $100 \mathrm{M}$ website views per year

At BMC, research is always in progress.

Learn more biomedcentral.com/submissions 